\title{
Voltage Sag Ride-through Performance of Virtual Synchronous Generator
}

\author{
Jaber Alipoor ${ }^{* a)}$ Non-member, Yushi Miura* Member \\ Toshifumi Ise ${ }^{*}$ Fellow
}

(Manuscript received Aug. 8, 2014, revised April 12, 2015)

\begin{abstract}
The Virtual Synchronous Generator (VSG) is an inverter control structure that supports power system stability by imitating a synchronous machine. Because of the restriction of inverter power and current, the VSG performance under disturbances should be evaluated and enhanced. In this paper, the response of the VSG unit to symmetrical and unsymmetrical voltage sags is assessed. A theoretical analysis that traces the trajectory of the state variable of the system during voltage sags is presented. The analysis confirms the effect of the characteristics of symmetrical and unsymmetrical voltage sags on the severity of their consequences. In addition, it is detected that two types of transients appear that must be mitigated: one is the transients during the voltage sag and the other one is the transients after voltage recovery. To prevent overcurrent during voltage sags, voltage amplitude control and output power control are implemented, and to suppress the transients after voltage recovery, virtual inertia control is implemented. The experimental results from a $10 \mathrm{kVA}$ VSG-controlled inverter confirm the effectiveness of the additional controllers.
\end{abstract}

Keywords: distributed generation, virtual synchronous generator, voltage sag

\section{Introduction}

Conventional enormous synchronous generators comprise rotating inertia due to their rotating parts. These generators are capable of injecting the kinetic energy preserved in their rotating parts to the power grid during disturbances or sudden changes. Therefore the system is robust against instability. On the other hand, penetration of Distributed Generating (DG) units in power systems is increasing rapidly. A power system with a big portion of inverter-based DGs is prone to instability due to lack of adequate balancing energy injection within the proper time interval. The solution can be found in the control scheme of inverter-based DGs. By embedding the mathematical model of a synchronous generator in the inverter, it can emulate the behavior of a real synchronous machine. In the Virtual Synchronous Generator (VSG) concept, the power electronics interface of the DG unit is controlled in a way to exhibit a reaction similar to that of a synchronous machine to a change or disturbance ${ }^{(1)}$.

The VSG concept and application were investigated in (2) (3). A similar concept under the title of Synchronverters is described in (4). The VSG systems addressed in (5)-(7) are designed to connect only an energy storage unit to the main grid. A linear and ideal model of synchronous machines is implemented in (8) to produce current reference signals for the hysteresis controller of the inverter. In this Virtual Synchronous Machine (VISMA), authors added an algorithm for small disturbance compensation to improve the quality of the grid voltage. Reference (9) introduces a mechanism for voltage, frequency and active and reactive power flow control of

a) Correspondence to: Jaber Alipoor. E-mail: alipoor@pe.eei.eng. osaka-u.ac.jp

* Osaka University

2-1, Yamada-oka, Suita, Osaka 565-0871, Japan
VSG. Our research group introduced another VSG design ${ }^{(10)}$ and added reactive power control to it to have a constant voltage at VSG terminals ${ }^{(11)}$.

Faults on transmission lines cause voltage drops in several points in power system that affects electrical equipment. Voltage sags (drops) are classified in several types based on the fault type. Three-phase fault on power line produces symmetrical voltage sag, while other fault types cause various unsymmetrical sags.

Several works addressed the effect of inverter based DG units on voltage sags in power system focusing on compensation effect of DGs ${ }^{(12)(13)}$. Reference (14) compared the performance of two control strategies in voltage sag ride-through improvement of a single phase converter-connected DG.

Since the VSG is inherently a power electronics-based unit, it is extremely sensitive to grid side faults and disturbances. Consequently, before practical usage, their operation must be evaluated under disturbances conditions. In this paper, VSG is tested under symmetrical and unsymmetrical voltage sags and the influence of the characteristics of voltage sags on the VSG transient current is investigated. To verify the results mathematically, current trajectory analysis in phase plane is introduced. The trajectory of system state variable (VSG current) is monitored in phase plane and its equations are extracted for during and after the sag. The effects of the characteristic of voltage sag can be observed clearly by this method. High magnitude transient current is the major hazardous consequence of voltage sags on inverter based DGs. To limit the overcurrent, three additional controllers of voltage amplitude control, output power control and virtual inertia control are embedded in the model and tested. Experiments were performed on a $10 \mathrm{kVA}$ VSG-controlled inverter and the results showed that the additional controllers enhanced the voltage sag ride-though capability of the VSG system. 
The structure of VSG system is reviewed in Sect. 2. In Sect. 3, the voltage sag types and characteristics are explained. In Sect. 4, the consequences of voltages sags on the VSG unit is monitored by simulation. In Sect. 5, the effect of the characteristics of voltages sags on its consequences is clarified by a theoretical analysis. In Sect. 6, three additional controllers are introduced to improve the voltage sag ridethrough performance of the VSG system. In Sect. 7, simulations corresponding to the experimental system of Sect. 8 were carried out and the performance of the proposed controllers was tested on it. Experimental results are represented in Sect. 8. Finally, conclusion is given in Sect. 9.

\section{Virtual Synchronous Generator Structure}

Figure 1 shows the control block diagram of the VSG system. In this scheme, a distributed resource (DR) is connected to the main power system via an inverter controlled based on the VSG concept. The model of the synchronous generator that is used in this paper is a cylindrical-rotor type synchronous generator connected to an infinite bus. The wellknown swing equation of synchronous generators is used as the heart of the VSG model:

$$
P_{\text {in }}-P_{\text {out }}=J \omega_{m} d \omega_{m} / d t+D \Delta \omega \ldots \ldots \ldots \ldots \ldots(1)
$$

where $P_{\text {in }}$ is input power (as same as the prime mover power in a synchronous generator), $P_{\text {out }}$ is output power, $J$ is the moment of inertia of the rotor, $\omega_{m}$ is the virtual angular velocity of the virtual rotor and $D$ is the damping factor. $\Delta \omega$ is given by $\Delta \omega=\omega_{m}-\omega_{\text {grid }}, \omega_{\text {grid }}$ being the grid frequency or the reference frequency when the grid is not available. Using voltage and current signals measured at the VSG terminals, its output power and frequency are calculated.

A governor model shown in Fig. 2 is implemented to tune the input power command based on the frequency deviation. Having the essential parameters, (1) can be solved by numerical integration. By solving this equation in each control cycle, the momentary $\omega_{m}$ is calculated and by passing through an integrator, the virtual mechanical phase angle, $\theta_{m}$ is produced. This phase angle and a voltage magnitude reference are used as the VSG output voltage angle and magnitude commands for generating PWM pulses.

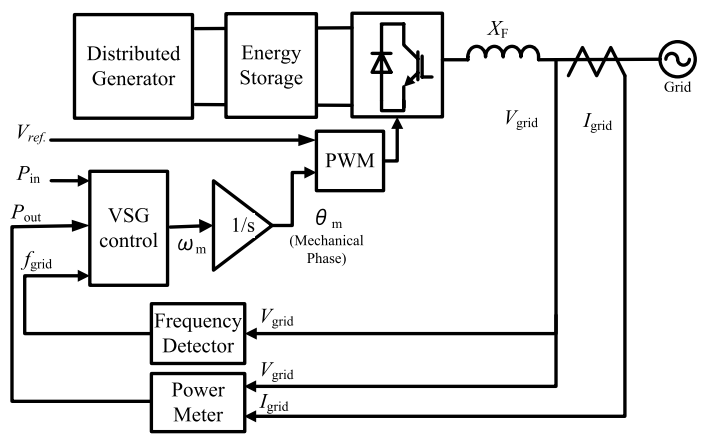

Fig. 1. Block diagram of the VSG unit

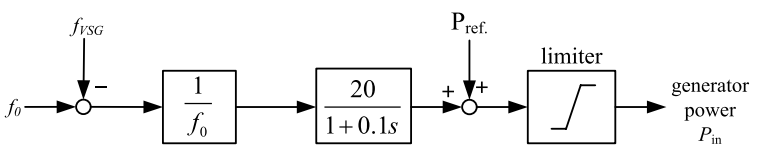

Fig. 2. Governor diagram

\section{Voltage Sags Types and Characteristics}

Voltage sag (dip) is a momentary drop in the RMS voltage of at least one of the three phases or line voltages. Voltage sags originate from short-term increase in current in power system due to fault or starting large loads ${ }^{(15)}$. Severity of the effects of voltage sags on equipment depends on the sag characteristics. Sag magnitude and duration are major characteristics. In this paper, we assume that the implemented sags are rectangular. At the instant when the sag begins, voltage of phase " $a$ ", $v_{a}$ is expressed by:

$$
\left.v_{a}(t)\right|_{t=t_{\text {sag }}}=V_{m} \sin \left(\theta_{0}\right)
$$

where $V_{m}$ is the phase voltage amplitude. Voltage phase angle at the sag beginning instant, $\theta_{0}$ is called initial point-on-wave. $\theta_{0}$ is considered as a characteristic of voltage sag that affects the response of appliance to voltage sag. For both symmetrical and unsymmetrical voltage sags, sag duration is the time interval between sag beginning and ending.

Voltage sags can be either symmetrical or unsymmetrical. If the individual phase voltages are equal and the phase angle relationship is $120^{\circ}$, the sag is symmetrical. Otherwise, the sag is unsymmetrical. Reference (16) classified the main voltage sags in 7 types.

Three-phase short circuits produce symmetrical sags classified as type A. In this type, voltage magnitudes of three phases decrease equally. For symmetrical sags, the magnitude of sag is the remained RMS voltage in per unit or percent of rated voltage that expressed by a parameter denoted as " $h$ ".

Type B voltage sags are one kind of unsymmetrical voltage sags that originate from single line-to-ground faults. Single line-to-ground faults after passing through a " $\Delta-Y$ " transformer and line-to-line faults on power lines produce voltage sags of type C. In this type, relative phase angles between voltages vectors also change. If the voltage sag of type $\mathrm{C}$ passes through a " $\Delta-Y$ " transformer, it will be converted to type $\mathrm{D}$ voltage sag.

For unsymmetrical sags, " $h$ " is a coefficient that appears in voltage equations and causes difference in their magnitude and/or phase angles as shown in Fig. 3. Lightest and severest characteristics of each voltage sag type are listed in Table 1.

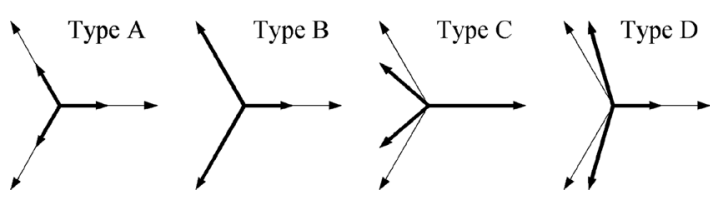

Fig. 3. Phasor diagram of voltage sag types for $h=0.5$

Table 1. Lightest and severest characteristics of voltage sags

\begin{tabular}{c|c|c|c|c}
\hline \multirow{2}{*}{ Sag type } & \multicolumn{2}{|c|}{ Lightest characteristics } & \multicolumn{2}{c}{ severest characteristics } \\
\cline { 2 - 5 } & duration & $\theta_{0}$ & duration & $\theta_{0}$ \\
\hline A & $k^{*} T^{* *}$ & - & $(k-1 / 2) T$ & - \\
B & $k T$ & $\pi / 2,3 \pi / 2$ & $(k-1 / 2) T$ & $0, \pi$ \\
C & $k T$ & $0, \pi$ & $(k-1 / 2) T$ & $\pi / 2,3 \pi / 2$ \\
D & $k T$ & $\pi / 2,3 \pi / 2$ & $(k-1 / 2) T$ & $0, \pi$ \\
\hline$* \in \mathbb{N}$
\end{tabular}

** $T$ : One cycle time period 


\section{VSG Subjected to Voltage Sags}

The VSG model discussed in Sect. 2 was simulated in PSCAD/EMTDC software. The parameters of the system are: $S_{\text {base }}=35 \mathrm{kVA}, f_{\text {base }}=60 \mathrm{~Hz}, X_{F}=42.4 \%, J=$ $5.63 \mathrm{kgm}^{2}$ and $D=17 \mathrm{pu}$. Voltage sags were applied to the VSG and its transient currents were investigated. In this section, results are summarized to voltage sags of types A and B. For all cases of simulation the voltage sag intensity parameter, $h$ is set to 0.1 .

Figure 4 shows the current waveforms of VSG subjected to voltage sag of type A with the duration of 2 cycles. Since this is the lightest characteristic of voltage sag, overcurrent happens only during voltage sag. Whereas, as shown in Fig. 5, for voltage sag of type A with the duration of 1.5 cycles there are current oscillations which appear after voltage recovery.

Initial point-of-wave must be taken into account for voltage sag of type B. Figure 6 shows the VSG response to a voltage sag of type B with the duration of 2 cycles and initial point-on-wave of $\pi / 2$ that is the kindest condition. Slight overcurrent happens in two phases during voltage sag. On the other hand, for the severest characteristics, which are the duration of 1.5 cycles and initial point-on-wave of zero, there are significant current oscillations during and after the voltage sag observed in Fig. 7.

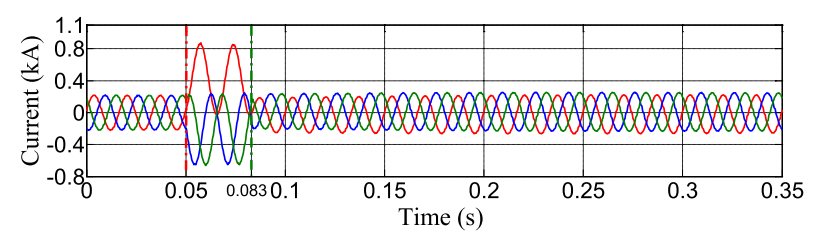

Fig. 4. Currents of the VSG subjected to a voltage sag of type A with the duration of 2 cycles and $h=0.1$

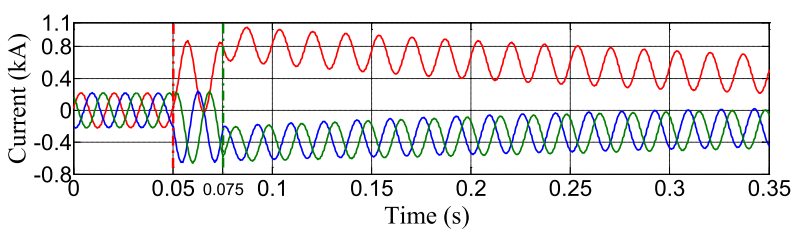

Fig. 5. Currents of the VSG subjected to a voltage sag of type A with the duration of 1.5 cycles and $h=0.1$

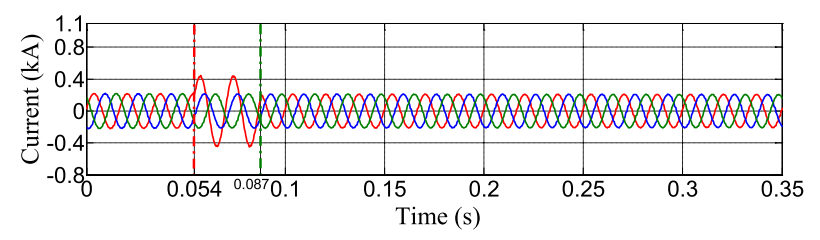

Fig. 6. Currents of the VSG subjected to a voltage sag of type B with the duration of 2 cycles, initial point-onwave of $\pi / 2$ and $h=0.1$

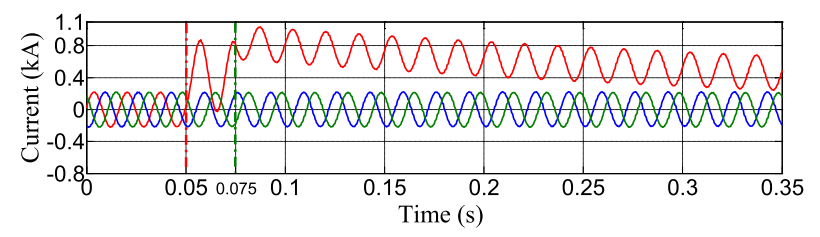

Fig. 7. Currents of the VSG subjected to a voltage sag of type B with the duration of 1.5 cycles, initial point-onwave of zero and $h=0.1$
The point achieved by simulations is that there are two sorts of transients that should be considered: one during the voltage sag and the other one after voltage recovery. In the next part, the effect of the voltage sag characteristics will be clarified analytically.

\section{State Variable Analysis in Phase Plane}

The disparity of the VSG responses to various sags and their characteristics can be illustrated by VSG state variable (current) analysis in phase plane. In addition, the origin of the transients after voltage recovery can be explained by this analysis.

5.1 Symmetrical Voltage Sags (Type A) Inverter output current during voltage sag is calculated by integrating the voltage in polar coordinate in stationary frame. To obtain the voltage equation in polar form, three-phase gird voltage is transferred into the stationary $d q$-frame and expressed in the form of:

$$
v(t)=v_{d}(t)+j v_{q}(t)=V_{m} e^{j\left(\omega t+\theta_{0}-\pi / 2\right)} \ldots \ldots \ldots \ldots
$$

where $V_{m}$ is the voltage vector magnitude in phase plane. This voltage vector rotates with the synchronous frequency on the stationary phase plane with the initial angle of $\theta_{0}-\pi / 2$. Using this transformation, the voltage equation of sag type $\mathrm{A}$ in the stationary polar coordinate is expressed as:

$$
v_{\text {sag }}(t)=h V_{m} e^{j\left(\theta_{0}-\pi / 2\right)} e^{j \omega_{\text {grid }} t} \ldots
$$

where $h V_{m}$ is the remained voltage amplitude and $\theta_{0}$ is the initial point-on-wave. As mentioned before, $h$ is the voltage sag intensity parameter varies from zero (zero remained voltage magnitude) to 1 (normal voltage). The fault current is calculated by integrating the voltage difference as:

$$
i_{\text {sag }}(t)=\frac{1}{L} \int_{0}^{t_{\text {sag }}}(1-h) V_{m} e^{j\left(\omega_{\text {grid }} t+\theta_{0}-\pi / 2\right)} d t \ldots \ldots
$$

where $i_{s a g}, L$ and $t_{s a g}$ are the fault current in the stationary reference frame, the interconnecting inductance and the sag ending time, respectively. Solving (5) and transferring to the synchronous reference frame yields:

$$
i_{\text {sag }}^{\text {synch }}(t)=(1-h) \frac{V_{m}}{\omega_{\text {grid }} L} e^{j\left(\theta_{0}-\pi\right)}\left(1-e^{-j \omega_{\text {grid }} t}\right) \ldots \ldots
$$

Based on (6), during voltage sag, current vector is circulating in the synchronous $d q$-frame phase plane with fixed radius as shown in Fig. 8 (the damping terms is neglected). The radius of the circle, $(1-h) V_{m} / L \omega_{\text {grid }}$, determines the oscillation magnitude during voltage sag. It is independent of the $\theta_{0}$ obviously.

If the duration of voltage sag is a multiple of full cycles, the state variable position at the sag ending moment will reach to its normal point (pre-sag point) after passing through circles in phase plane. When the voltage recovered from the sag, the state variable has to move to its normal point and since it is extremely close to it, minimum oscillations happen after voltage sag. Whereas if the duration is half a cycle more than any number of full cycles, the state variable position has maximum distance to its normal point at the sag ending moment based on (6). It means that transient current has its maximum magnitude. The transient current must settle down on 


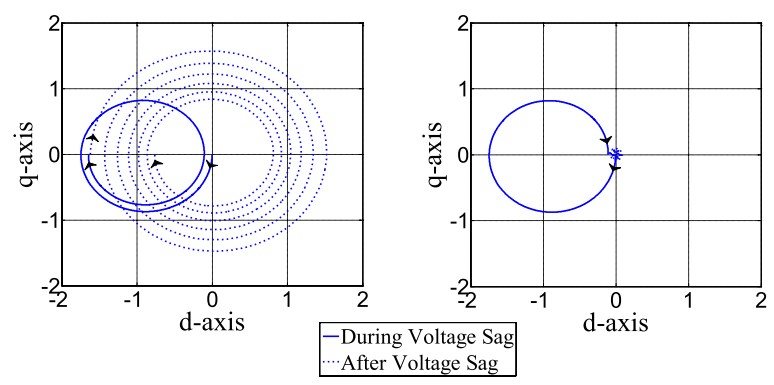

Fig. 8. VSG current trajectory in phase plane during (solid line) and after (dotted line) voltage sag type A with $h=0.1$ : (a) Voltage sag with the duration of 1.5 cycles and (b) Voltage sag with the duration of 1 cycle

the origin of coordinate (current before fault is neglected) after voltage recovery. The second transient can be expressed as:

$$
i_{\text {after sag }}^{\text {synch }}(t)=2(1-h) \frac{V_{m}}{\omega_{\text {grid }} L} e^{j\left(\theta_{0}-\pi\right)} e^{-j \omega t} \ldots \ldots \ldots \ldots
$$

Equation (7) is a circular trajectory with the center coinciding with the origin. The radius of trajectory after voltage sag has its maximum possible value proving that the assumed duration is the severest one. Figure 8 includes the current paths in phase plane. In this paper, $d$-axis is taken as the reference axis and phase " $a$ " and $q$-axis lead $d$-axis by $\theta_{0}$ and $\pi / 2$, respectively. Part (a) of Fig. 8 is related to the sag with the duration of 1.5 cycles and $h=0.1$. At the sag ending point the state variable goes through circles with a large radius (dotted line) that causes severe current transient. While in part (b) of the figure, when the duration is one full cycle, there is a small distance between the position of the variable after and before the sag and light transient happens.

It must be noted that the transient during voltage sag is not affected by the sag duration. However, the sag magnitude parameter $h$, determines the transient severity during voltage sag. If the voltage sag is shallow ( $h$ close to unity) and/or if the sag lasts for a relatively long time, the state variable transients during voltage sag will settle down at the center of the solid-line circles before voltage sag ends. Afterwards, when voltage amplitude is recovered, the state variable has to move to its normal point from the center of the first transient circles. It means that the oscillations will have identical amplitude regardless of the duration of the voltage sag.

5.2 Unsymmetrical Voltage Sags The same analysis with more intense mathematical work is performed for voltage sag of type B as the representative of unsymmetrical voltage sags. The three-phase phasor expressions of voltage sag type B are as follows:

$$
\left\{\begin{array}{l}
V_{a}=h V_{r m s} \\
V_{b}=-\frac{1}{2} V_{r m s}-j \frac{\sqrt{3}}{2} V_{r m s} \ldots \ldots \ldots \ldots \ldots \ldots \ldots \\
V_{c}=-\frac{1}{2} V_{r m s}-j \frac{\sqrt{3}}{2} V_{r m s}
\end{array}\right.
$$

Transforming into polar form in the stationary coordinate yields:

$$
v_{\text {sag }}(t)=\frac{V_{m}}{3}\left((h+2) e^{j\left(\omega_{\text {grid }} t+\theta_{0}-\pi / 2\right)}\right.
$$

$$
\left.+(h-1) e^{-j\left(\omega_{\text {grid }} t+\theta_{0}-\pi / 2\right)}\right) \cdot
$$

After integrating the voltage difference between the inverter and grid, the fault current in the synchronous frame is given as follows:

$$
\begin{aligned}
i_{\text {sag }}^{\text {synch }}(t)= & \frac{V_{m}(1-h)}{3 L \omega_{\text {grid }}}\left(-e^{j \theta_{0}}+2 \cos \theta_{0} e^{-j \omega_{\text {grid }} t}\right. \\
& \left.-e^{-j \theta_{0}} e^{-2 j \omega_{\text {grid }} t}\right) \ldots \ldots \ldots \ldots \ldots \ldots \ldots \ldots
\end{aligned}
$$

It is observed that the coefficient $\cos \theta_{0}$ appears in the current equation and affects its magnitude during oscillation. The form of (10) on the phase plane is not exactly circular and depends on $\theta_{0}$. The characteristics of the voltage sags that result in the maximum absolute value of (10) are the critical characteristics for this type of voltage sag. The initial pointson-wave of zero and $\pi$ bring forth the maximum oscillations during voltage sag type $\mathrm{B}$ and with these values of $\theta_{0}$, when the duration of the sag is a multiple of a half-cycle, the state variable position has maximum distance to its normal point. When voltage is recovered at this moment, the state variable returns to its normal point with severest oscillation similar to one of the symmetrical voltage sag, i.e., the circular trace in the phase plane. The terms $e^{-2 j \omega_{\text {grid }} t}$ in (10) indicates that the current oscillates with twice of the system frequency during unsymmetrical voltage sags.

The mildest characteristics of voltage sag type B can be deduced from (10) as well. The initial points-on-wave of $\pi / 2$ and $3 \pi / 2$ result in the lightest oscillations during voltage sag. For these initial points-on-wave, the duration of a multiple of a half-cycle and the duration of an odd multiple of a quarter-cycle have the mildest and severest consequences after sag, respectively (only the oscillatory component with double system frequency exists in (10)). For unsymmetrical voltage sags also, if the duration is long or if the sag is shallow, the transient will settle down before voltage recovery. When voltage is recovered in this condition, the transients after voltage sag has fixed magnitude only related to $h$, in regardless of the duration and initial point-on-wave.

\section{Voltage Sag Ride-through Enhancement}

Three approaches are added to the VSG system to limit the overcurrent during and after voltage sag. Figure 9 shows the VSG system with the additional controls.

6.1 Voltage Amplitude Control Subsystem A in Fig. 9 calculates the Root Mean Square (RMS) value of grid voltage and uses it as the reference voltage for inverter output. By this control, when grid voltage drops during voltage sag, inverter output voltage also will be reduced to prevent overcurrent. The RMS voltage is calculated by $V_{R M S}=$ $\sqrt{V_{d}^{2}+V_{q}^{2}}$. During unsymmetrical voltage sags, the calculated RMS voltage has oscillation as mentioned in Sect. 5. A first order Low Pass Filter (LPF) shown in subsystem A of Fig. 9 is used to remove the oscillation.

6.2 Output Power Control Since inverter output power is proportional to the product of the inverter and grid voltages, once the output voltage follows the grid voltage, inverter output power must be limited proportional to the square of the grid voltage. Subsystem B calculates the output power reference of VSG proportional to the square of the grid voltage. 


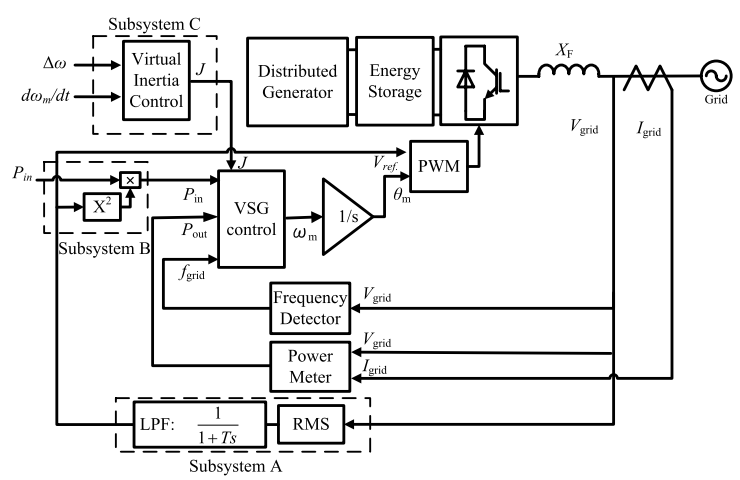

Fig. 9. VSG unit with the additional controls for voltage sag ride-through enhancement

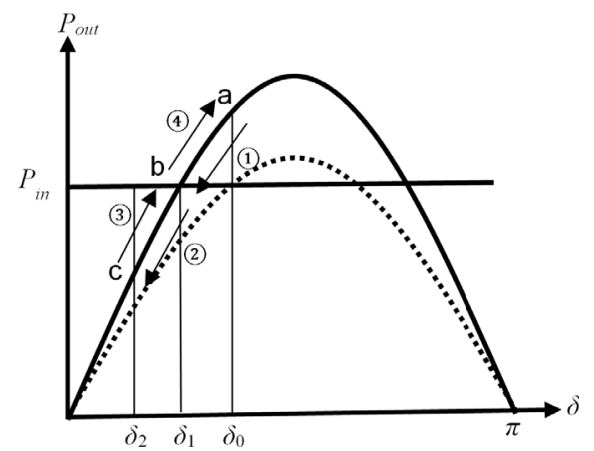

Fig. 10. Power-angle curve of a synchronous machine subjected to a fault. When a fault happens, operating point moves on the dotted line and reaches to the point $\delta_{0}$. After fault clearance, it returns to the original curve and oscillates around the equilibrium point $\delta_{1}$

Table 2. Machine modes during oscillation

\begin{tabular}{|c|c|c|c|c|}
\hline Segment & $\boldsymbol{\Delta \omega}$ & $\boldsymbol{d} \omega_{\boldsymbol{m}} / \boldsymbol{d} \boldsymbol{t}$ & Mode & $\boldsymbol{J}$ \\
\hline $\mathrm{a} \rightarrow \mathrm{b}$ & $\Delta \omega<0$ & $d \omega_{m} / d t<0$ & Accelerating & $J_{\text {big }}$ \\
\hline $\mathrm{b} \rightarrow \mathrm{c}$ & $\Delta \omega<0$ & $d \omega_{m} / d t>0$ & Decelerating & $J_{\text {small }}$ \\
\hline $\mathrm{c} \rightarrow \mathrm{b}$ & $\Delta \omega>0$ & $d \omega_{m} / d t>0$ & Accelerating & $J_{\text {big }}$ \\
\hline $\mathrm{b} \rightarrow \mathrm{a}$ & $\Delta \omega>0$ & $d \omega_{m} / d t<0$ & Decelerating & $J_{\text {small }}$ \\
\hline
\end{tabular}

6.3 Virtual Inertia Control Consider the powerangle curve of Fig. 10. When a fault happens, power-angle relation follows the dotted line curve and load angle moves to the point $\delta_{0}$. After the fault clearance, operating point moves along the original power-angle curve and load angle oscillates around the equilibrium point $\delta_{1}$. The machine condition during each phase of an oscillation cycle is summarized in Table 2. It should be noted that the sign of the $d \omega_{m} / d t$ does not determine acceleration or deceleration by itself; whereas, its sign respect to the sign of the relative angular velocity defines the acceleration or deceleration. For example during transition from points "c" to "b" in Fig. 10, both of $d \omega_{m} / d t$ and $\Delta \omega$ are positive and act in the same direction; therefore, it is an acceleration period. Whereas, when they have opposite signs like transition from points " $b$ " to " $a$ ", it is a deceleration period.

The derivative of angular velocity, $d \omega_{m} / d t$ indicates the rate of acceleration or deceleration. Considering (1), it is observed that this rate has a reverse relation to the moment of inertia, $J$. Based on this fact, one can select a large value of $J$ during acceleration phases ("a" to "b" and "c" to "b")

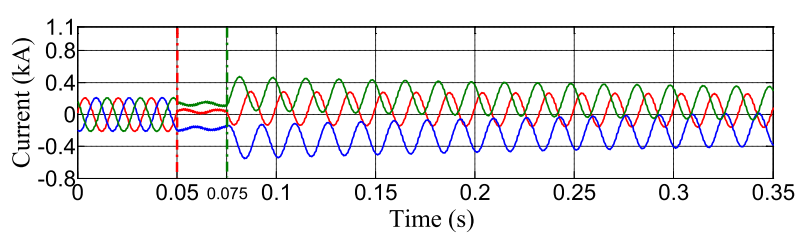

Fig. 11. Currents of the VSG with the voltage amplitude, output power, and virtual inertia controls, subjected to a voltage sag of type A with the duration of 1.5 cycles and $h=0.1$ (the severest case)

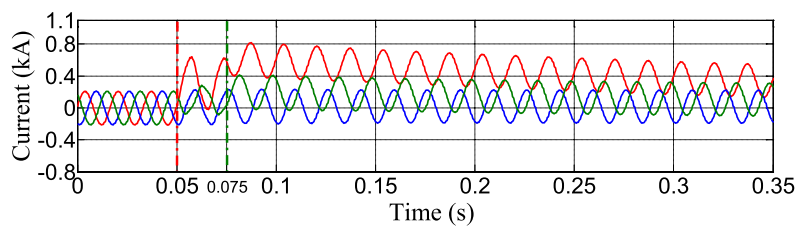

Fig. 12. Currents of the VSG with the voltage amplitude, output power, and virtual inertia controls, subjected to a voltage sag of type $B$ with the duration of 1.5 cycles, initial point-on-wave of zero and $h=0.1$ (the severest case)

to reduce the acceleration, and a small value of $J$ during deceleration phases ("b" to "c" and "b" to "a") to boost the deceleration. Using the transient energy function analysis, the authors proved that this algorithm brings in a damping effect that suppresses the transient quickly ${ }^{(17)}$. The big moment of inertia $J_{b i g}$ and the small one $J_{\text {small }}$ can be chosen within a wide range depending on the rated power so that the difference between $J_{b i g}$ and $J_{\text {small }}$ determines the damped power in each half-cycle of oscillation. The subsystem $\mathrm{C}$ in Fig. 9 adopts the value of the virtual inertia based on the stated algorithm summarized in Table 2.

The simulations of Sect. 4 were repeated for the VSG with the voltage amplitude, output power, and virtual inertia controls under the severest characteristics condition of voltage sags. To let the voltage amplitude control be quick enough, the LPF of the voltage reference loop of Fig. 9 was not included during the simulations. Figure 11 shows the current of the VSG subjected to a critical sag type A. The overcurrent that appeared during and after voltage sag in Fig. 5 was eliminated effectively by the additional controllers. The current position in phase plane was moved from its normal position toward the origin of the phase plane. This small distance from the normal position caused a slight transient after voltage recovery that was damped slowly.

In the case of unsymmetrical voltage sags, without the LPF in voltage control loop, the calculated RMS voltage will be oscillatory. On the other hand, using the LPF imposes a delay in following the grid voltage and consequently, reduces the effectiveness of the controller. Figure 12 shows the simulation result for the severest voltage sag of type B. It is observed that the overcurrent was reduced compared to Fig. 7. However, because of the oscillatory voltage reference, it was not reduced as effectively as sag type A.

\section{Simulation Results}

A simulation model similar to the experimental system of next section was built in PSCAD/EMTDC. The system configuration and parameters are shown in Figs. 13 and 14 and 


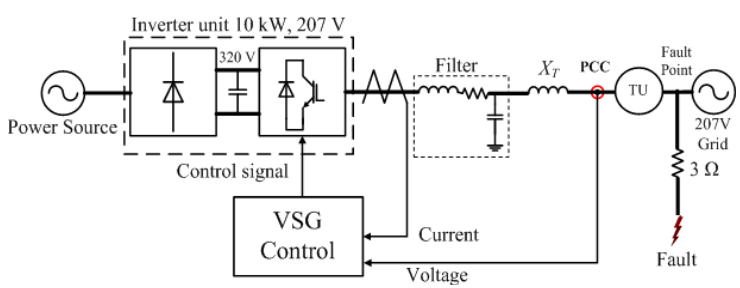

Fig. 13. Simulation system

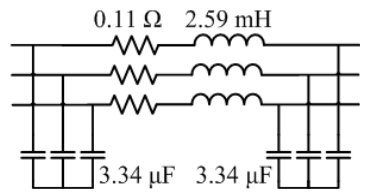

Fig. 14. The $\pi$ model of a $40 \mathrm{~km}$ transmission line

Table 3. The specifications of the simulation system

\begin{tabular}{|l|c|}
\hline Base Power & $10 \mathrm{kVA}$ \\
\hline Base Frequency & $60 \mathrm{~Hz}$ \\
\hline Switching Frequency & $14 \mathrm{kHz}$ \\
\hline Dc-link Voltage & $320 \mathrm{~V}$ \\
\hline Dc-link Capacitor & $4.7 \mathrm{mF}$ \\
\hline Filter Stray Resistance & $0.23 \%$ \\
\hline Filter Inductive Reactance & $8.8 \%$ \\
\hline Filter Capacitor VAR & $1.62 \%$ \\
\hline Resonance Frequency of LC Filter & $1.59 \mathrm{kHz}$ \\
\hline$X_{T}$ & $9.68 \%$ \\
\hline Damping factor & $17 \mathrm{pu}$ \\
\hline Moment of inertia $J[H]$ & $0.563 \mathrm{kgm}^{2}[4.0 \mathrm{~s}]$ \\
\hline$J_{\text {big }}\left[H_{\text {big }}\right]$ & $0.563 \mathrm{kgm}^{2}[4.0 \mathrm{~s}]$ \\
\hline$J_{\text {small }}\left[H_{\text {small }}\right]$ & $0.1 \mathrm{kgm}^{2}[0.7 \mathrm{~s}]$ \\
\hline
\end{tabular}

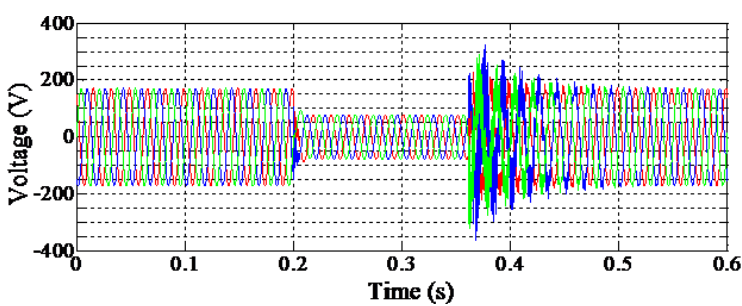

Fig. 15. Symmetrical voltage sag at PCC with $45 \%$ remained voltage

Table 3. In the simulation, the transformer was replaced by its equivalent reactance, $X_{T}$ and all system operated at $207 \mathrm{~V}$ nominal voltage. Furthermore, the fault path resistance was chosen $3 \Omega$ to have deeper voltage sags. To see the voltage profile during fault, the VSG was disconnected and threephase fault stablished for 10 cycles of system frequency. The phase-to-neutral voltages of the point of common coupling (PCC) affected by the fault is shown in Fig. 15. The remained voltage in this case is $45 \%$ of the nominal voltage $(h=0.45)$. However, the voltage drop in the presence of VSG is less due to the compensation by VSG.

In the next step, the VSG system without the additional controller was connected and a fault happened while the VSG was injecting $2.6 \mathrm{~kW}$ power to the grid. The RMS voltage at PCC, VSG current, and the dc link voltage waveforms are presented in Fig. 16. In this simulation, the RMS voltage is calculated with a smoothing time constant of $0.0159 \mathrm{~s}$ (the
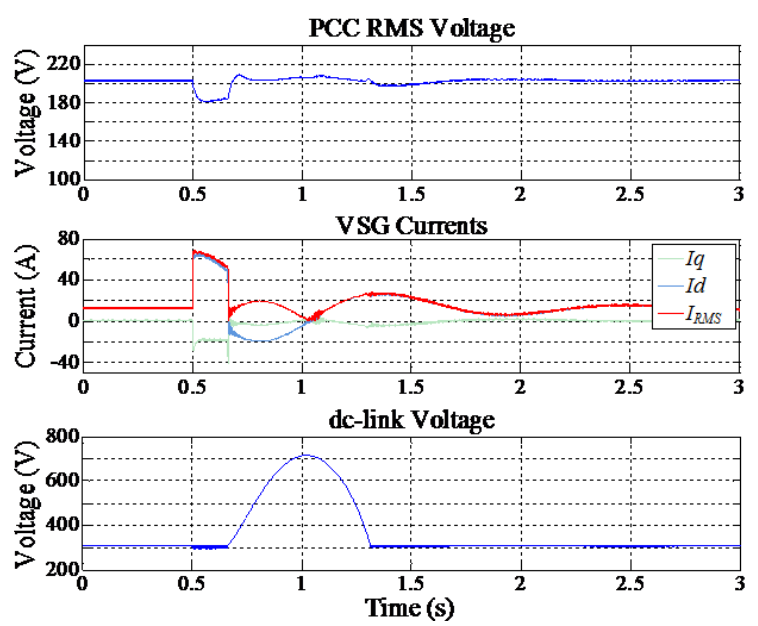

Fig. 16. PCC RMS voltage, VSG currents, and dc-link voltage of the system without the additional controllers, affected by voltage sag
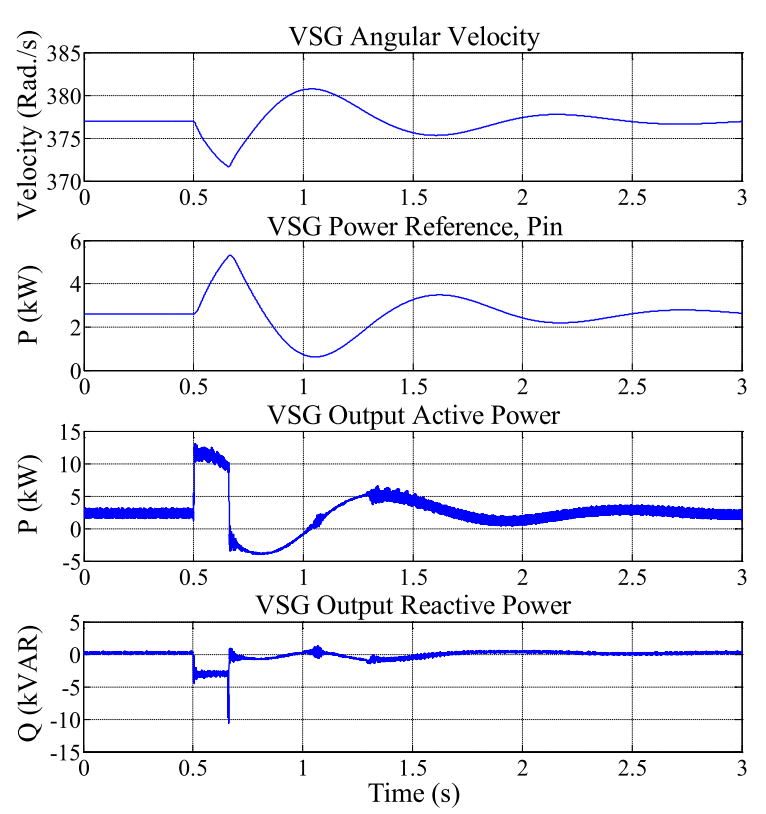

Fig. 17. Angular velocity, power reference calculated by governor, output active power, and output reactive power of VSG without the additional controllers, affected by voltage sag

cut-off frequency of the LPF is $10 \mathrm{~Hz}$ ). As it is observed, RMS current raised immediately up to $70 \mathrm{~A}$ when voltage drop at PCC happened. Moreover, when the voltage magnitude was recovered, the current transient went to negative level (reverse current) and increased the dc-link voltage. The transient during voltage sag may result in the overcurrent failure and the transient after voltage recovery may result in the dc-link overvoltage failure.

The waveforms of the VSG angular velocity, power reference calculated by governor, VSG output active power, and VSG output reactive power are shown in Fig. 17. During transients, the governor calculates the power reference in opposite of the frequency oscillation to maintain the VSG frequency at system nominal frequency. The active power of VSG has a waveform similar to the $I_{d}$ of Fig. 16 . The reverse power that increases the dc-link voltage is observed 

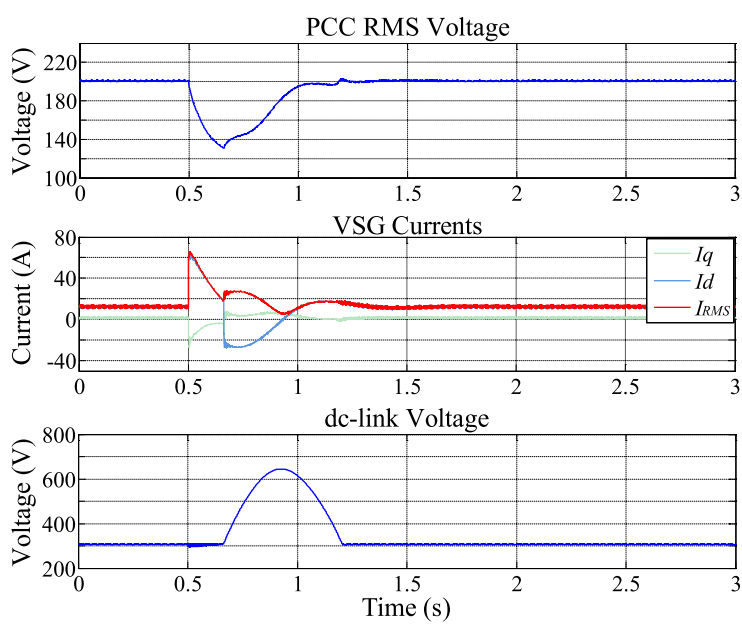

Fig. 18. PCC RMS voltage, VSG currents, and dc-link voltage of the system with the additional controllers, affected by voltage sag

more clearly in power curve. The reactive power transient is similar to the transient of $I_{q}$ of Fig. 16.

To mitigate the possible failures, the proposed voltage amplitude control and output power control were added to limit the overcurrent current during voltage sag, and the virtual inertia control were added to eliminate the after sag transients and prevent dc-link overvoltage. The RMS voltage at PCC, VSG current, and dc-link voltage waveforms are shown in Fig. 18. The PCC voltage sag was deeper because the current injected by VSG was reduced by additional controllers. With the voltage amplitude and output power controls, although the transient current peak at the sag starting moment was reduced to some extent, however because of the delay in RMS voltage calculation, the voltage amplitude control was not able to apply the voltage reference equal to the PCC voltage promptly and the overcurrent prevention performance was limited by this delay. During the voltage sag, since the voltage reference followed the grid voltage, the overcurrent fell down with a steep ramp. The dc-link voltage rise was reduced by around $70 \mathrm{~V}$ via the virtual inertia control. However, by setting a smaller value for $J_{\text {small }}$ this controller is more effective.

The VSG angular velocity, power reference calculated by governor, VSG output active power, and VSG output reactive power are shown in Fig. 19. The virtual inertia control suppressed the VSG angular velocity quickly. By the output power control, the power reference calculated by governor is reduced at the sag starting moment proportional to the square of the PCC voltage.

However the power reference was increased after a short while to regulate the frequency. Similar to $I_{d}$, The active power transient during voltage sag was reduced by the additional controllers. After voltage recovery, the transient of output active power had the negative amplitude almost equal to the curve of Fig. 17 that was without additional controllers. However, this transient was suppressed quickly by the virtual inertia control and did not last for the same while as Fig. 17. Therefore the reverse energy and consequently the dc-link voltage rise is reduced. The $J$ calculated by virtual inertia control is shown in Fig. 20. It is observed that the value of
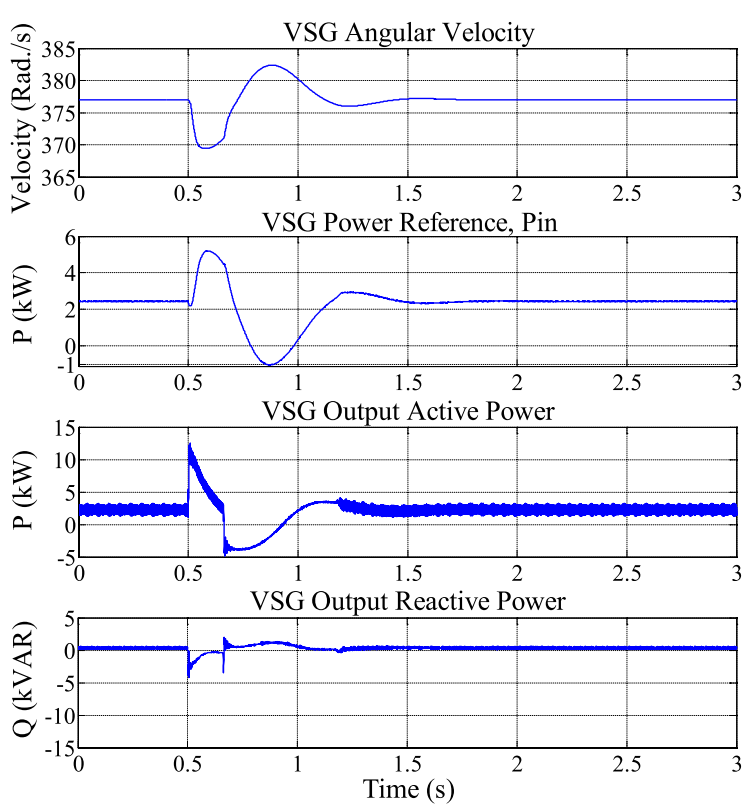

Fig. 19. Angular velocity, power reference calculated by governor, output active power, and output reactive power of VSG with the additional controllers, affected by voltage sag
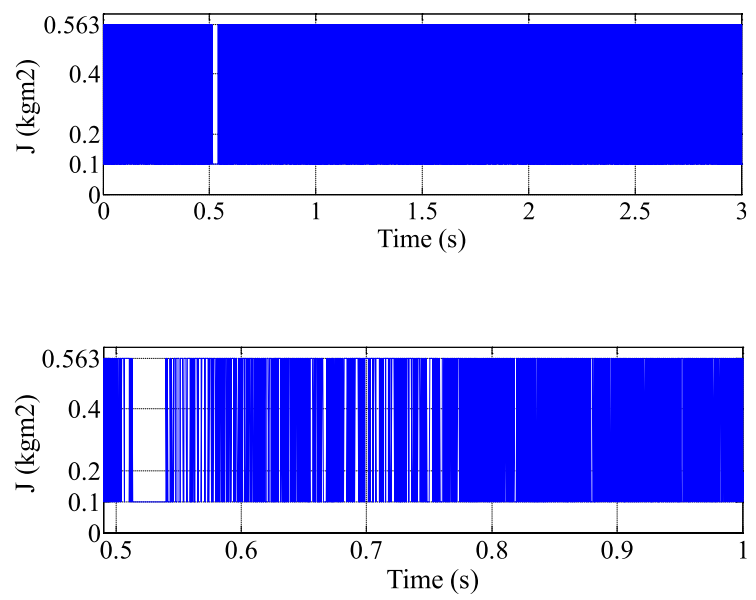

Fig. 20. (a): $J$ calculated by variable inertia scheme; (b): Expanded graph of $J$

inertia is chattering during steady state operation. This chattering appears because of the slight variation of the angular velocity around the equilibrium point. However, the chattering can be removed by setting a threshold for the $\Delta \omega$ in the virtual inertia control algorithm. It is carried out by replacing the $\Delta \omega>0$ and $\Delta \omega<0$ in Table 2 by $\Delta \omega>\varepsilon$ and $\Delta \omega<\varepsilon$, respectively which $\varepsilon$ is a negligible positive value. It this paper, this threshold is not applied since experience showed that the chattering $J$ has a better performance in frequency regulation and voltage ripple reduction.

As mentioned before, the delay in sensing, calculating and filtering the PCC voltage to calculate the VSG voltage reference is the main obstacle of the effectiveness of the voltage amplitude control. To see the effect of this delay, the smoothing time constant of the RMS voltage calculation was reduced to $1 \mathrm{~ms}$ and the simulation was performed. The result is shown in Fig. 21. It is observed the delay in RMS voltage calculation was reduced and thereby, the overcurrent 

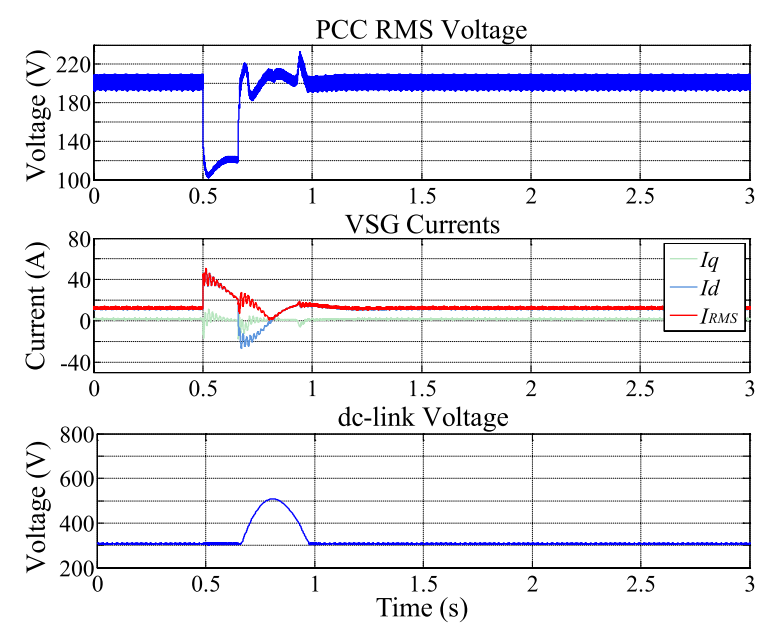

Fig. 21. PCC RMS voltage and VSG currents of the system with the additional controllers (with RMS voltage calculation time constant $1 \mathrm{~ms}$ ), affected by voltage sag

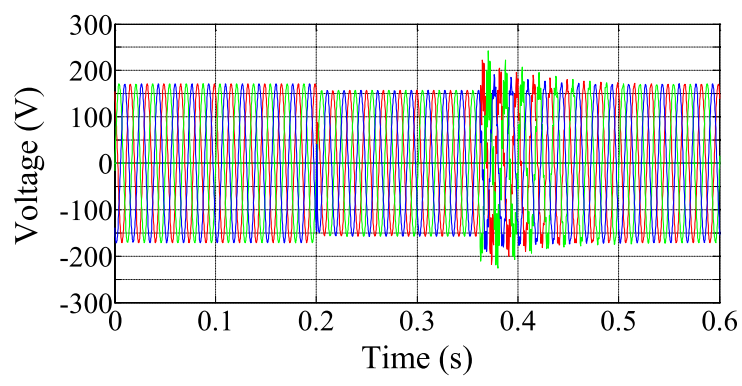

Fig. 22. Symmetrical voltage sag at PCC with $92 \%$ remained voltage

at the sag starting moment was reduced considerably. The LPF is essential especially in case of unsymmetrical voltage sags that the calculated RMS voltage has oscillation with double system frequency which must be removed. Moreover, in practical systems, the delay is not only by the filter, but also the sensors and measurement devices comprise considerable delays.

The experimental system of Sect. 8 can be tested solely under shallow voltage sags due to current limitation of the inverter. In order to verify the compliance of the simulation results with the subsequent experiments, simulations under shallow voltage sags were performed. For this purpose, the resistance of the fault path of Fig. 13 was changed to $10 \Omega$. When the three-phase fault was applied, a light voltage sag with $92 \%$ remained voltage that is shown in Fig. 22 appeared at the PCC point of Fig. 13 with disconnected inverter.

While injecting $1 \mathrm{~kW}$ power to the grid, the VSG system was subjected to the light voltage sag in two conditions of with and without additional controllers. Figures 23 and 24 include the waveforms of the RMS voltage at PCC, the VSG currents, and the dc-link voltage with and without the proposed controllers, respectively. At $t=0.5 \mathrm{~s}$ when the voltage dropped, the VSG currents raised instantly. For the system without the additional controllers, the overcurrent persisted for a while during voltage sag as observed in Fig. 23; whereas for the system with the additional controllers, the overcurrent started to decrease immediately shown in Fig. 24. Moreover, the oscillation after voltage recovery disappeared quickly by
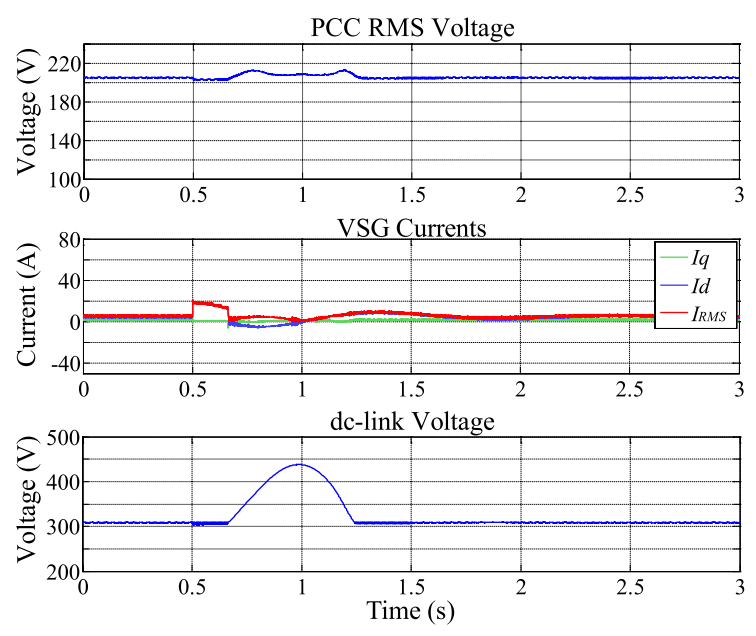

Fig. 23. PCC RMS voltage, VSG currents, and dc-link voltage of the system without the additional controllers, affected by the shallow voltage sag
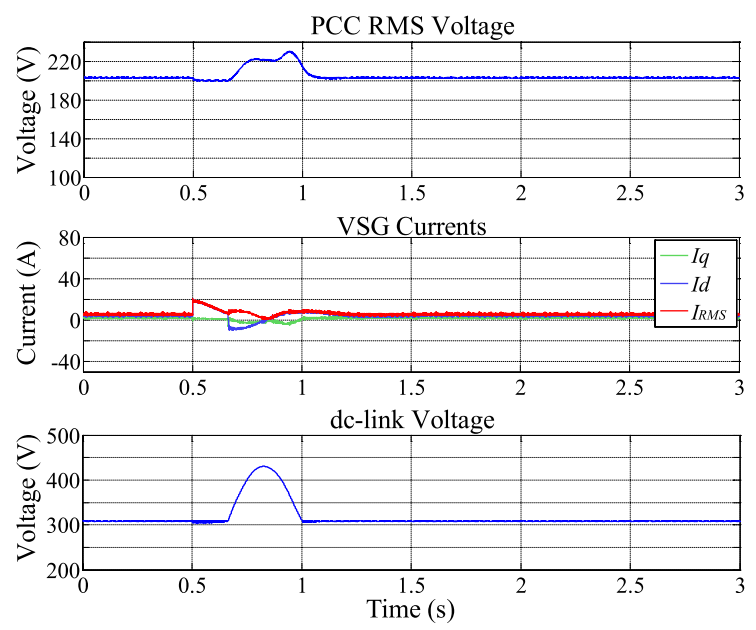

Fig. 24. PCC RMS voltage, VSG currents, and dc-link voltage of the system with the additional controllers, affected by the shallow voltage sag

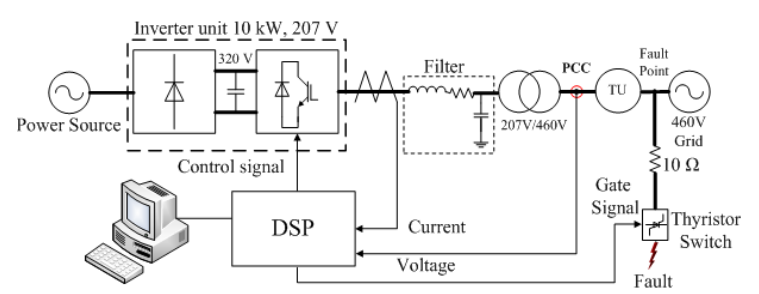

Fig. 25. Experimental system

the additional controllers. The quick elimination of the oscillation after voltage recovery resulted in a smaller and shortertime dc-link voltage rise for the system with the additional controllers.

\section{Experimental Results}

A laboratory-scale system is used to investigate the voltage sag ride-through performance of the VSG. The overall system configuration is depicted in Fig. 25 and the main parameters of the system are presented in Table 4 . The transmission unit (TU) in Fig. 25 simulates the $\pi$ model of a $40 \mathrm{~km}$ transmission line shown in Fig. 14.

Due to the strict overcurrent limitation of the inverter unit, 
Table 4. The specifications of the experimental system

\begin{tabular}{|l|c|}
\hline Base Power & $10 \mathrm{kVA}$ \\
\hline Base Frequency & $60 \mathrm{~Hz}$ \\
\hline Switching Frequency & $14 \mathrm{kHz}$ \\
\hline Dc-link Voltage & $320 \mathrm{~V}$ \\
\hline Dc-link Capacitor & $4.7 \mathrm{mF}$ \\
\hline Filter Stray Resistance & $0.23 \%$ \\
\hline Filter Inductive Reactance & $8.8 \%$ \\
\hline Filter Capacitor VAR & $1.62 \%$ \\
\hline Resonance Frequency of LC Filter & $1.59 \mathrm{kHz}$ \\
\hline Transformer Reactance & $9.68 \%$ \\
\hline Damping factor & $17 \mathrm{pu}$ \\
\hline Moment of inertia $J[H]$ & $0.563 \mathrm{kgm}^{2}[4.0 \mathrm{~s}]$ \\
\hline$J_{\text {big }}\left[H_{\text {big }}\right]$ & $0.563 \mathrm{kgm}^{2}[4.0 \mathrm{~s}]$ \\
\hline$J_{\text {small }}\left[H_{\text {small }}\right]$ & $0.1 \mathrm{kgm}^{2}[0.7 \mathrm{~s}]$ \\
\hline
\end{tabular}

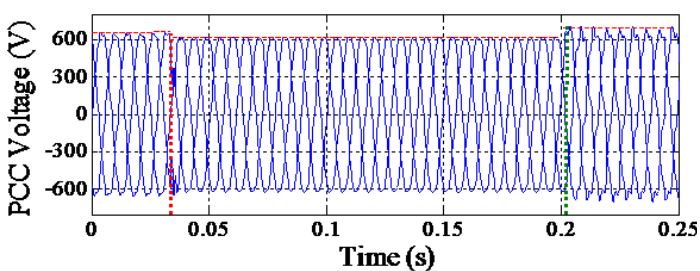

Fig. 26. Type A (symmetrical) voltage sag at PCC due to symmetrical three-phase fault

when a deep voltage sag happens, the VSG unit is stopped by its protection system. Therefore, mild voltage sags with magnitudes bigger than $90 \%$ with the duration of 10 cycles were tested on this system and voltage sag ride-through performance of the VSG unit was evaluated. For light voltage sags, since the state variable position in phase plane at the sag ending moment does not change considerably by the characteristics, the characteristics do not affect the severity of transient oscillation. The voltage amplitude control in experiments has a LPF with $10 \mathrm{~Hz}$ cut-off frequency $(T=0.0159 \mathrm{~s}$ in Fig. 9).

8.1 Symmetrical Voltage Sag The voltage sag shown in Fig. 26 appeared due to three-phase short circuit happened at the fault point and measured at the Point of Common Coupling (PCC) indicated in Fig. 25. The voltage magnitude during voltage sag is $92 \%$ of the normal value. The fault was controlled by switching thyristors in the fault path. The initial point-on-wave can be adjusted by a phase detection algorithm in the DSP unit. Since the exact turn-off point of the thyristors can not be controlled by the gate signal, the duration of the voltage sag will have utmost a half-cycle error. However, as mentioned before, the duration and initial pointon-wave are not effective for shallow voltage sags. Therefore, these characteristics were not investigated in the experiments.

To assess the performance of the additional controls, first the VSG unit without the controllers is subjected to the voltage sag illustrated in Fig. 26. As stated formerly, two transient states happen: the transient during voltage sag and the one after voltage recovery. To see the importance of the transient after voltage recovery, the VSG was subjected to the voltage sag while injecting $1 \mathrm{~kW}$ power to the grid and its current in synchronous $d q$-coordinate was monitored. Figure 27 shows the currents and dc-link voltage in this condition. The oscillations after voltage recovery caused power
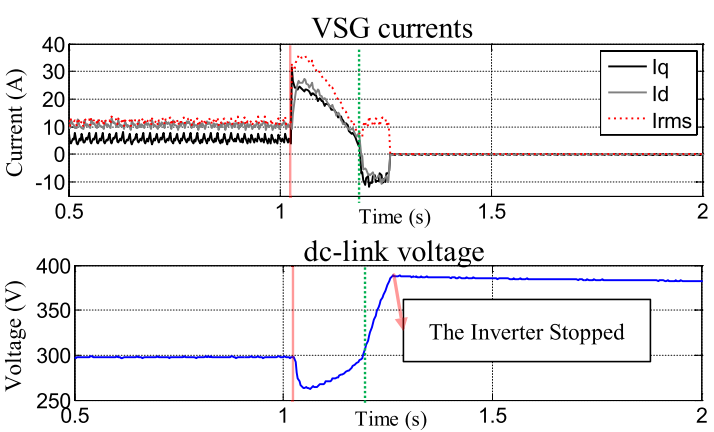

Fig. 27. Currents and dc-link voltage of the VSG with $1 \mathrm{~kW}$ output power and without additional controller subjected to voltage sag type A
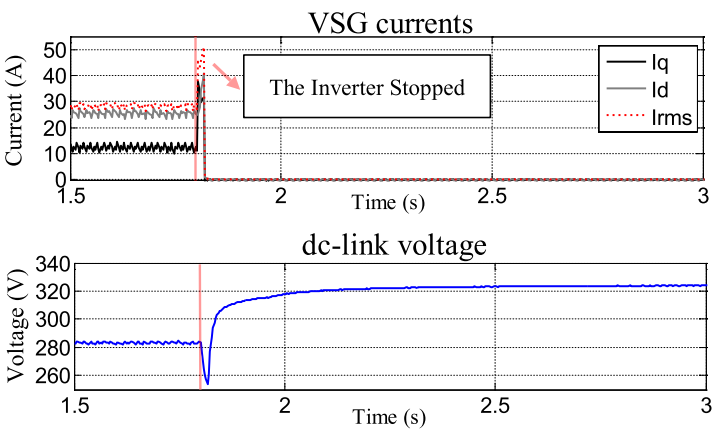

Fig. 28. Currents and dc-link voltage of the VSG with $2.6 \mathrm{~kW}$ output power and without additional controller subjected to voltage sag type A

and current oscillation which went to negative value. This reverse current increased the dc-link voltage and resulted in the failure. Using an energy storage unit with high rate of charging or a larger dc-link capacitor can prevent the dc-link overvoltage failure. However, the objective is to prevent the failure of the existing system by a proper control scheme. It is observed later that virtual inertia control will prevent this kind of failure. This case corresponds to the simulation case of Fig. 23. The dc-link voltage rise of the simulation case shown in Fig. 23 happened in this experiment case as well which resulted in the failure.

During the voltage sag, the VSG current is raised due to the voltage difference between the VSG and the grid. Since the voltage sag amplitude (the remained voltage) is high in this research (that means a mild voltage sag), the initial current of the VSG affects the fault ride-through performance. When the VSG unit was loaded at $2.6 \mathrm{~kW}$, the voltage sag type A was applied. Figure 28 shows that the VSG current raised sharply and VSG was stopped. It can be concluded that for lower loading levels, the oscillations after fault recovery causes the failure and for higher loading levels, the overcurrent during voltage sag results in the failure.

In the next step, only the voltage amplitude control and output power control are activated. When the VSG output power was the inconsiderable value of $1 \mathrm{~kW}$, the type A voltage sag happened. As it is observed in Fig. 29, the oscillation after voltage sag fell to the negative level and activated the dc-link voltage protection.

The VSG current and dc-link voltage affected by voltage sag when the VSG power is $2.6 \mathrm{~kW}$ is shown in Fig. 30 . In this condition, the voltage amplitude and power control 


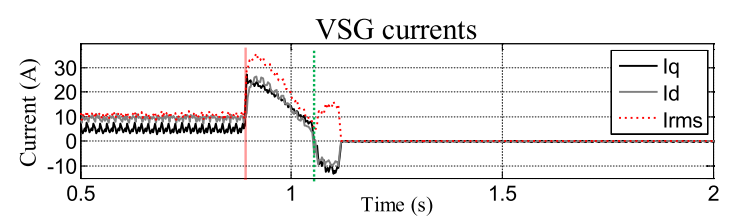

dc-link voltage

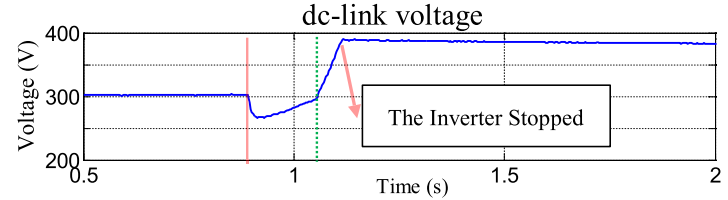

Fig. 29. Currents and dc-link voltage of the VSG with $1 \mathrm{~kW}$ output power and with voltage amplitude and output power controller subjected to voltage sag type A

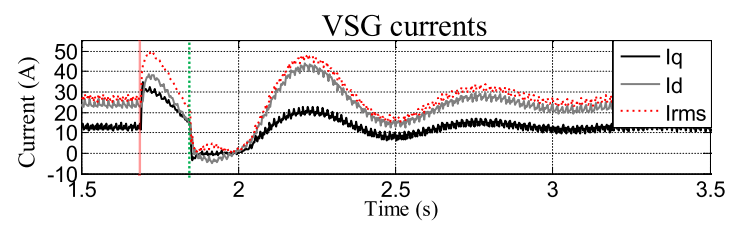

dc-link voltage

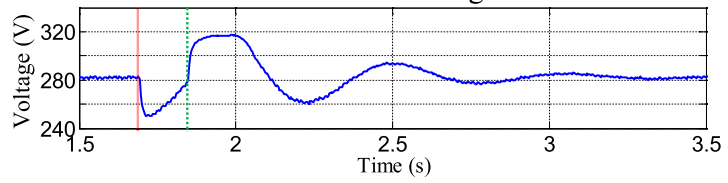

Fig. 30. Currents and dc-link voltage of the VSG with $2.6 \mathrm{~kW}$ output power and with voltage amplitude and output power controller subjected to voltage sag type A
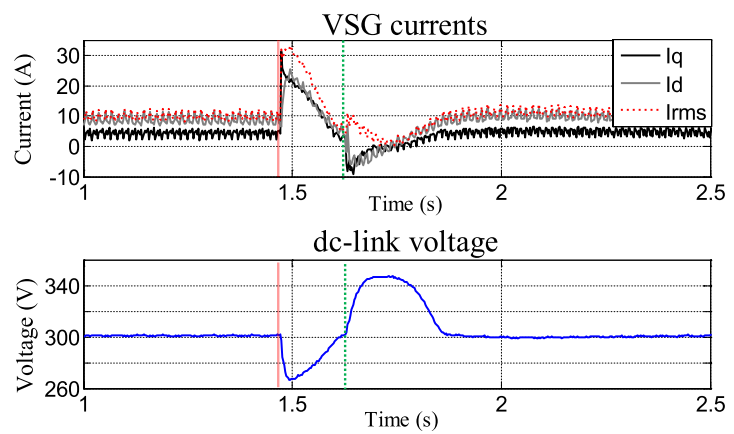

Fig. 31. Currents and dc-link voltage of the VSG with $1 \mathrm{~kW}$ output power and with voltage amplitude, output power, and virtual inertia controller subjected to voltage sag type A

banned the overcurrent to some extent and the VSG was able to pass-through the fault. When the voltage sag starts, it is expected that the voltage amplitude controller calculate the grid RMS-voltage and apply it as the voltage reference of the inverter. Although the overcurrent magnitude was reduced slightly; however, severe current transient happened. It is because of the delay in sensing, filtering, and applying the voltage reference. In spite of this technical shortcoming, the VSG unit was able to ride-through this voltage sag. It should be noted that the RMS value of $I_{d}$ and $I_{q}$ is concerned as the threatening overcurrent.

In the next experiment, all of the additional controllers were activated. First the VSG with the low output power of $1 \mathrm{~kW}$ was subjected to the voltage sag type A. As it is observed in Fig. 31, the inertia control suppressed the after sag oscillations by imposing a damping effect. This case
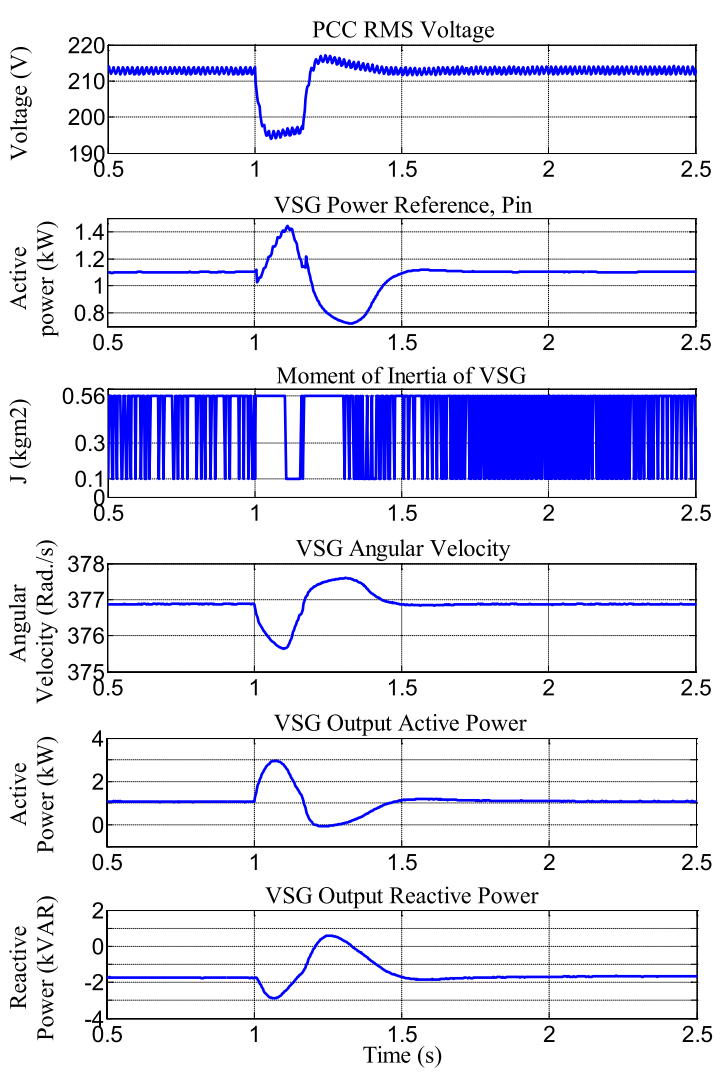

Fig. 32. PCC RMS voltage, power reference calculated by governor, the Alternating Inertia, angular velocity, VSG output active power, and the VSG output reactive power of the system with $1 \mathrm{~kW}$ output power reference and with voltage amplitude, output power, and virtual inertia controller subjected to voltage sag type A

corresponds to the simulation case of Fig. 24. Similar to the simulation case, the overcurrent that appeared at the voltage drop moment started to decrease immediately by the voltage amplitude and output power controllers. Unlike the AC power source of the experimental system, the power source on the left hand side of the simulation model of Fig. 13 is an ideal AC source without internal reactance. Therefore the drop in the dc-link voltage during voltage sag was instantaneously compensated by the current from the diode rectifier in the case of simulation. On the other hand, the drop in dclink voltage was caused by the delay of compensation from the diode rectifier due to internal reactance of the $\mathrm{AC}$ power source on the left hand side of Fig. 25 in the case of experiments. This dc voltage drop during voltage sag does not affect the performance of the additional controllers as shown in Figs. 32 and 34.

PCC RMS voltage, power reference calculated by governor, virtual inertia, angular velocity, VSG output active power, and VSG output reactive power for the experiment case with $1 \mathrm{~kW}$ output power reference and with voltage amplitude, output power, and virtual inertia controller subjected to voltage sag type A are depicted in Fig. 32. It is observed that when the voltage dropped, the power reference calculated by governor has been slightly reduced at first, because it is proportional to the square of RMS voltage by the output power control. However, it has been increased by governor afterwards to compensate the frequency drop. It should 

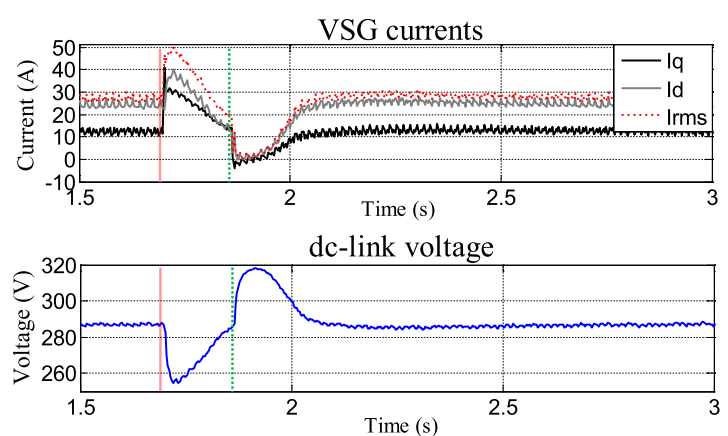

Fig. 33. Currents and dc-link voltage of the VSG with $3 \mathrm{~kW}$ output power and with voltage amplitude, output power, and virtual inertia controller subjected to voltage sag type A
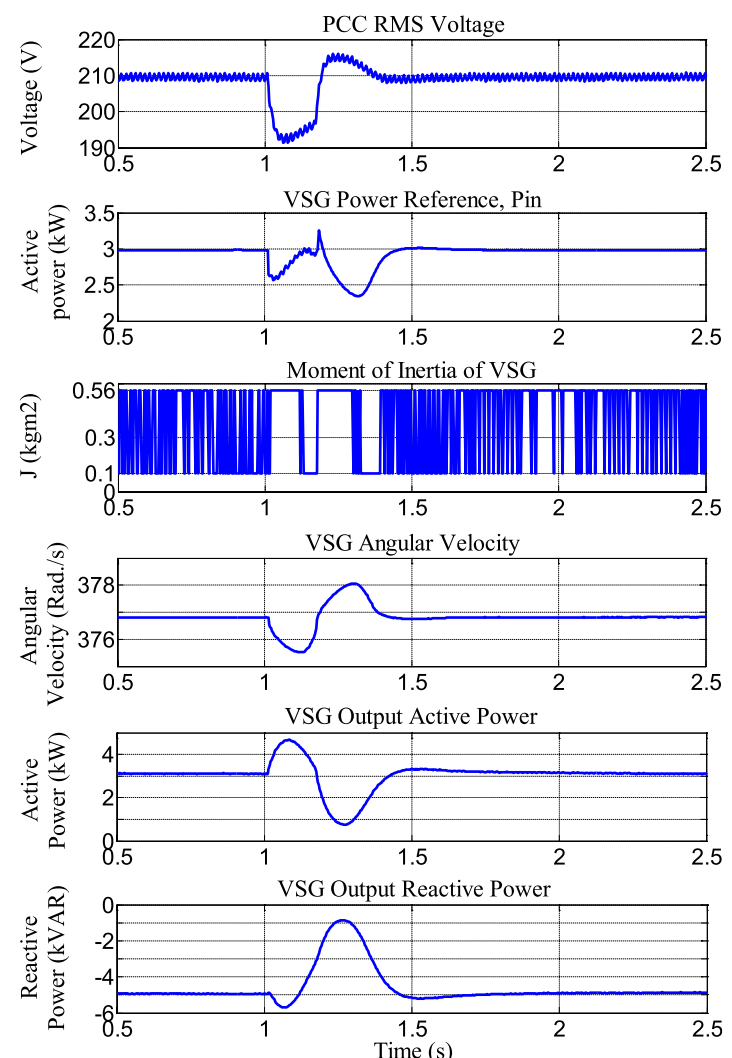

Fig. 34. PCC RMS voltage, power reference calculated by governor, the Alternating Inertia, angular velocity, VSG output active power, and the VSG output reactive power of the system with $3 \mathrm{~kW}$ output power reference and with voltage amplitude, output power, and virtual inertia controller subjected to voltage sag type A

be noted that the overcurrent at the sag starting moment has maximum value and should be limited. Accordingly, the reduction in the power reference at the beginning of voltage sag was effective enough to prevent the overcurrent failure in this case. Although, the oscillation after voltage recovery was suppressed by virtual inertia control, still transient excursions are observed in the active and reactive power waveforms. However, the magnitude of the transients was reduced and the inverter was able to ride-through them. It will be shown in the unsymmetrical voltage sag experiment that the virtual inertia control is so effective that even for very lower output power $(200 \mathrm{~W})$, the oscillation after voltage recovery

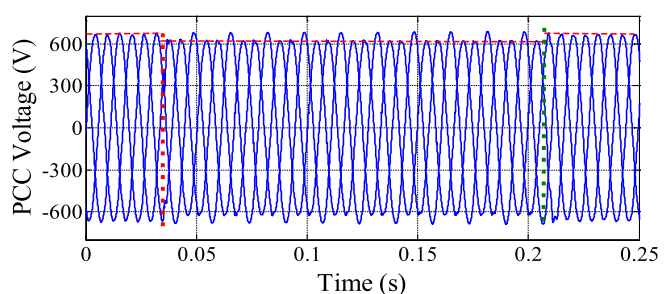

Fig. 35. Type C voltage sag at PCC due to phase-tophase fault
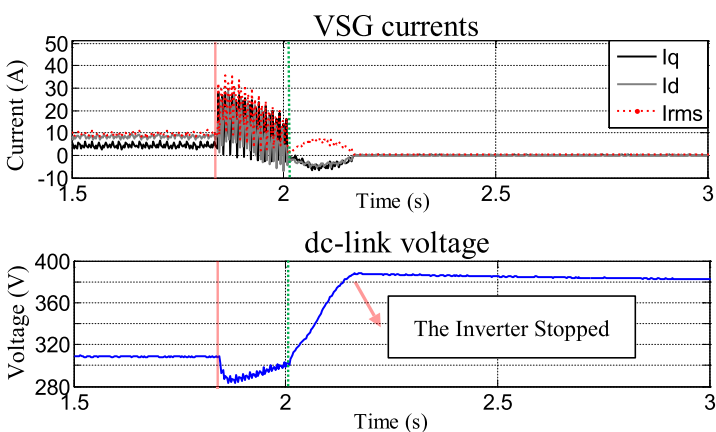

Fig. 36. Currents and dc-link voltage of the VSG with $1 \mathrm{~kW}$ output power and without additional controller subjected to voltage sag type $\mathrm{C}$

does not cause a failure.

In high loading condition, the overcurrent at the sag starting moment is perilous. Figure 33 shows the currents and dclink voltage of the VSG with $3 \mathrm{~kW}$ output power equipped with the additional controllers subjected to the voltage sag type A. Because of the delay in voltage control, output voltage did not follow the grid voltage promptly; therefore, overcurrent appeared right away when the sag starts. However, it fell down quickly and the VSG passed through the sag even with high output power of $3 \mathrm{~kW}$.

PCC RMS voltage, power reference calculated by governor, virtual inertia, angular velocity, VSG output active power, and VSG output reactive power for the experiment case with $3 \mathrm{~kW}$ power, and virtual inertia controller subjected to voltage sag type A is shown in Fig. 34. The PCC RMS voltage value shown in this figure is used by voltage amplitude and power controls. As it is observed, the calculated RMS voltage had a delay that resulted in a high current at the beginning of the voltage sag. Nonetheless, the additional controllers limited this current peak to some extent so that the inverter was able to ride-through the voltage sag.

8.2 Unsymmetrical Voltage Sag The VSG unit was also evaluated under unsymmetrical voltage sag condition. A phase-to-phase fault with the line-to-line resistance of $20 \Omega$ happened at the fault point of Fig. 25 which produced type $\mathrm{C}$ voltage sag at PCC with $93 \%$ remained voltage at phases " $a$ " and " $b$ " as shown in Fig. 35.

Figures 36 and 37 show the experiment results of VSG subjected to voltage sag type $\mathrm{C}$ at $1 \mathrm{~kW}$ and $2.6 \mathrm{~kW}$ output power, respectively. In these cases, the behavior of the VSG without any additional controller was similar to that of the symmetrical voltage sag. The only difference is the form of overcurrent during voltage sag that has an oscillatory component with twice of the system frequency. The VSG unit with output power less than $1 \mathrm{~kW}$ failed due to the transients after 

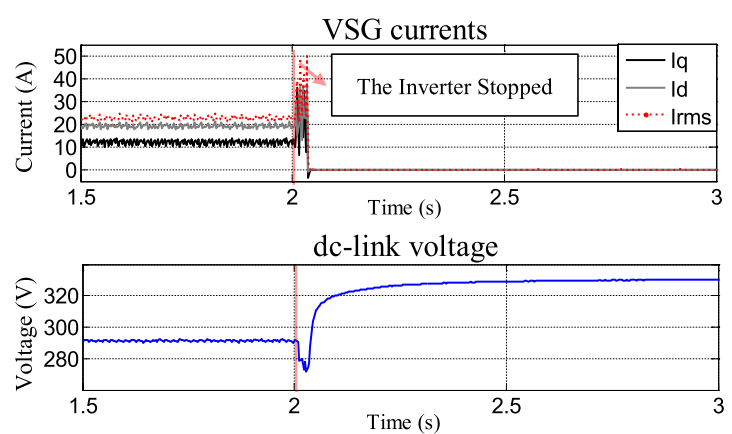

Fig. 37. Currents and dc-link voltage of the VSG with $2.6 \mathrm{~kW}$ output power and without additional controller subjected to voltage sag type $\mathrm{C}$
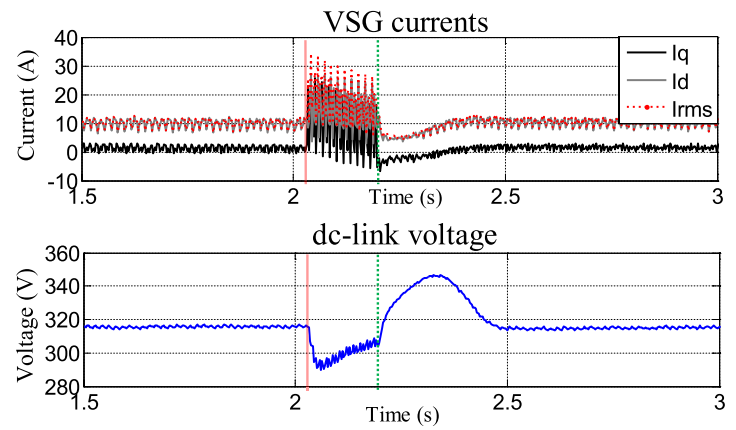

Fig. 38. Currents and dc-link voltage of the VSG with $200 \mathrm{~W}$ output power and with voltage amplitude, output power, and virtual inertia controller subjected to voltage sag type $\mathrm{C}$
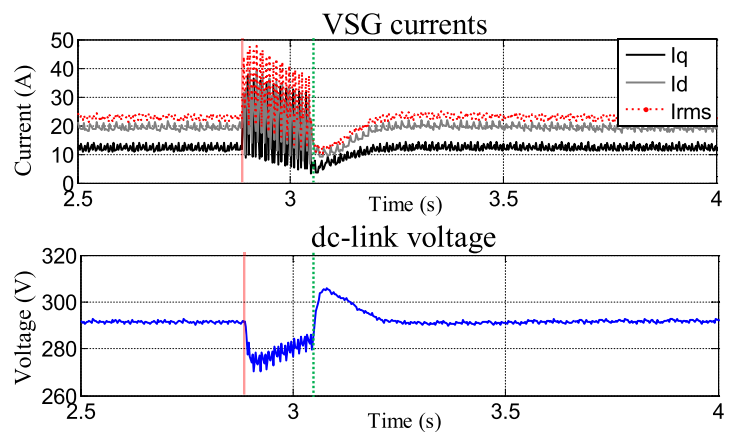

Fig. 39. Currents and dc-link voltage of the VSG with $2.6 \mathrm{~kW}$ output power and with voltage amplitude, output power, and virtual inertia controller subjected to voltage sag type $\mathrm{C}$

the sag, and it failed due to overcurrent during the sag when the output power is higher than $2.6 \mathrm{~kW}$. Figure 38 depicts the current and dc-link voltage of the VSG with voltage sag ridethrough controllers, at low output power of $200 \mathrm{~W}$, subjected to the unsymmetrical voltage sag type C. It is observed that when the additional controllers were activated, the oscillation after voltage recovery was eliminated and hence, the failure because of the dc-link overvoltage was prevented.

The same experiment was done when the VSG works at $2.6 \mathrm{~kW}$ output power and the results are represented in Fig. 39. It is observed that the additional controllers improved the voltage sag ride-through capability of the VSG system effectively. However, there might be a problem in calculating the RMS voltage of the grid during unsymmetrical voltage sag. Since the $d q$-component voltages oscillate with double system frequency during unsymmetrical voltage sag, the calculated RMS voltage is oscillatory as well. The oscillatory RMS voltage is not suitable to be used as the voltage reference of VSG. The LPF of the voltage amplitude controller removes this oscillation. However, in accordance with the theoretical analysis of Sect. 5.2, the transient current during unsymmetrical voltage sag has double system frequency component that is observed in Figs. 36 to 39 .

\section{Conclusion}

VSG has been invented to support grid stability by inserting virtual inertia into power system. VSG may be vulnerable in fault condition because of its power electronics basis. Evaluation of voltage sag consequences is the first step of VSG protection in fault condition. Symmetrical and unsymmetrical types of voltage sag were applied to the VSG and its response was monitored by checking the transient current. It was observed that when a VSG unit is subjected to a voltage sag, two sorts of transients appear during and after voltage sag that their severity depends on the characteristics of the voltage sag. If a symmetrical voltage sag (type A) lasts a half cycle more than a multiple of full cycles, severest current oscillation appears after voltage recovery. For unsymmetrical voltage sags, initial point-on-wave is also important. The initial points-on-wave of zero and $\pi$ result in the severest transients during and after voltage sag for both voltage sag types $\mathrm{B}$ and $\mathrm{D}$; whereas for type C, $\pi / 2$ and $3 \pi / 2$ are the critical ones. With the stated critical initial points-on-wave, the durations of a half cycle more than any multiple of full cycles produce the severest transients after voltage recovery. The origin of the transients was explained by analyzing the state variable trajectory in phase plane. By extracting the radius of the circulations of the transient current in phase plane, the severity of the transients can be evaluated.

Finally, voltage amplitude control and output power control were added to the VSG system to suppress the overcurrent during voltage sag and virtual inertia control was implemented to eliminate the oscillation after voltage recovery. Experimental results showed that the additional controls improved voltage sag ride-through capability of VSG effectively for symmetrical and unsymmetrical voltage sags.

\section{References}

( 1 ) J. Alipoor, Y. Miura, and T. Ise: "Evaluation of Virtual Synchronous Generator (VSG) Operation under Different Voltage Sag Conditions", in IEEJ Conference on Power Technology and power systems, Tokyo, JAPAN, pp.41-46, PE-12-60, PSE-12-76 (2012)

( 2 ) J. Driesen and K. Visscher: "Virtual Synchronous Generators", in IEEE Power and Energy Society General Meeting - Conversion and Delivery of Electrical Energy in the 21st Century, pp.1-3 (2008)

( 3 ) T. Loix, S. De Breucker, P. Vanassche, J. Van den Keybus, J. Driesen, and K. Visscher: "Layout and Performance of the Power Electronic Converter Platform for the VSYNC Project", in IEEE Powertech Conference, pp.1-8 (2009)

( 4 ) Q.C. Zhong and G. Weiss: "Synchronverters: Inverters That Mimic Synchronous Generators", IEEE Trans. Industrial Electronics, Vol.58, No.4, pp.1259-1267 (2011)

( 5 ) M.P.N. van Wesenbeeck, S.W.H. de Haan, P. Varela, and K. Visscher: "Grid Tied Converter with Virtual Kinetic Storage", in IEEE Powertech Conference, Bucharest, pp.1-7 (2009)

( 6 ) M. Torres and L.A.C. Lopes: "Virtual synchronous generator control in autonomous wind-diesel power systems", in IEEE Electrical Power \& Energy 
Conference (EPEC), Montreal, pp.1-6 (2009)

( 7 ) V. Karapanos, S. de Haan, and K. Zwetsloot: "Real Time Simulation of a Power System with VSG Hardware in the Loop", in 37th Annual Conference on IEEE Industrial Electronics Society (IECON), Melbourne, pp.3748-3754 (2011)

( 8 ) R. Hesse, D. Turschner, and H.-P. Beck: "Micro grid stabilization using the virtual synchronous machine", in International Conference on Renewable Energies and Power Quality (ICREPQ’09), Spain (2009)

( 9 ) Y. Xiang-zhen, S. Jian-hui, D. Ming, L. Jin-wei, and D. Yan, "Control Strategy for Virtual Synchronous Generator in Microgrid", in 4th International Conference on Electric Utility Deregulation and Restructuring and Power Technologies (DRPT), pp.1633-1637 (2011)

(10) K. Sakimoto, Y. Miura, and T. Ise: "Stabilization of a Power System with a Distributed Generators by a Virtual Synchronous Generator function", in 8th IEEE international conference on Power electronics- ECCE Asia, Jeju, Korea, pp.1498-1505 (2011)

(11) T. Shintai, Y. Miura, and T. Ise: "Reactive Power Control for Load Sharing with Virtual Synchronous Generator Control", in Power Electronics and Motion Control Conference (IPEMC), pp.846-853 (2012)

(12) K.J.P. Macken, M.H.J. Bollen, and R.J.M. Belmans: "Mitigation of voltage dips through distributed generation systems", IEEE Trans. on Industry Applications, Vol.40, No.6, pp.1686-1693 (2004)

(13) B. Renders, K. De Gusseme, W. Ryckaert, K. Stockman, L. Vandevelde, and M.H.J. Bollen: "Distributed Generation for Mitigating Voltage Dips in LowVoltage Distribution Grids", IEEE Transactions on Power Delivery, Vol.23, No.3, pp.1581-1588 (2008)

(14) B. Renders, W.R. Ryckaert, K. De Gusseme, K. Stockman, and L. Vandevelde: "Improving the Voltage Dip Immunity of Converter-connected Distributed Generation Units", Elsevier, Renewable Energy, Vol.33, No.5, pp.1011-1018 (2007)

(15) M.H.J. Bollen: "Voltage Recovery After Unbalanced and Balanced Voltage Dips in Three-Phase Systems", IEEE Transactions on Power Delivery, Vol.4, No.18, pp.1376-1381 (2003)

(16) M.H.J. Bollen: "Characterization of Voltage Sags Experienced by ThreePhase Adjustable-speed Drives", IEEE Transactions on Power Delivery, Vol.12, No.4, pp.1666-1671 (1997)

(17) J. Alipoor, Y. Miura, and T. Ise: "Distributed generation grid integration using virtual synchronous generator with adoptive virtual inertia", in 13th IEEE Energy Conversion Congress and Exposition (ECCE), pp.4546-4552 (2013)
Jaber Alipoor (Non-member) received the B.Sc. degree from the Electrical Eng. Dept. of Mazandaran University, Iran, in 2007 and M.Sc. degree from the Electrical Engineering Department of Shahed University, Tehran, Iran in 2010. At the present, he is the $\mathrm{PhD}$ student of Osaka University, Japan. His especial fields of interest are Power System Stability, Power Quality, and Distributed Power Generation.

Yushi Miura (Member) received a Doctor of Engineering's degree in

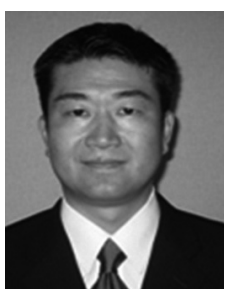
Electrical and Electronic Engineering from Tokyo Institute of Technology in 1995. He was employed by Japan Atomic Energy Research Institute from 1996 to 2004, and is presently an associate professor of $\mathrm{Di}$ vision of Electrical, Electronic and Information Engineering, Osaka University. He is studying applications of power electronics to power systems.

Toshifumi Ise (Fellow) received the Doctor of Engineering degree in

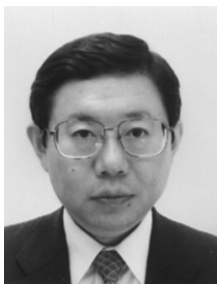
electrical engineering from Osaka University, Japan in 1986. Currently, he is the professor of Division of Electrical, Electronic and Information Engineering at Graduate School of Engineering, Osaka University. His research interests are in the areas of power electronics and applied superconductivity including power quality issues such as voltage sag compensator, superconducting magnetic energy storage (SMES) and new distribution systems including many distributed generations. 